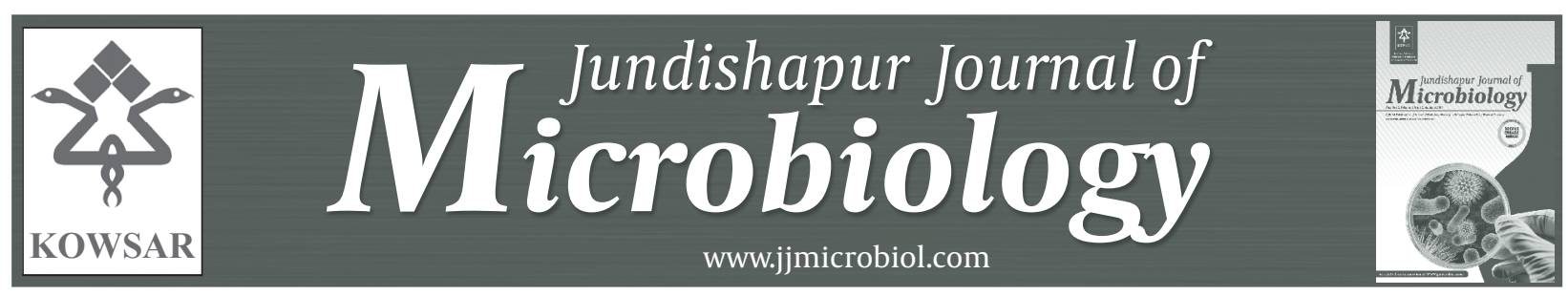

\title{
Prevalence of Helicobacter pylori Infection evaluated by Stool antigen test in Khuzestan Province since September to October 2009, south-west of Iran: a population based study
}

\author{
Abdolhassan Talaiezadeh ${ }^{1}$, Mehrdad Borhani ${ }^{2}$, Mojteba Moosavian ${ }^{2}$, Abdullah Rafiei ${ }^{2}$, Ab- \\ dul Kazem Neisi ${ }^{2}$, Eskandar Hajiani ${ }^{1,}$, Seid Mohammad Alavi ${ }^{2}$, Abdrasul Nik khu ${ }^{2}$ \\ ${ }^{1}$ Research Institute for Infectious Diseases of Digestive System, Ahvaz Jundishapur University of Medical Sciences, Ahvaz, IR Iran \\ 2 Jundishapur Infectious and Tropical Diseases Research Centre, Ahvaz Jundishapur University of Medical Sciences, Ahvaz,IR Iran \\ * Corresponding author: Eskandar Hajiani, Research Institute for Infectious Diseases of Digestive system, Ahvaz Jundishapur University of Medical Sciences, \\ Ahvaz, IR Iran.Tel.: +98-6115530222, Fax: +98-6113340074, E-mail: ehajiani@gmail.com
}

\section{A B S T R A C T}

Background: Although infection with Helicobacter pylori is a global health problem, its prevalence is different among countries. Serologic tests for the diagnosis of $H$. pylori infection are limited by low accuracy rates and lack of validation. Recent studies indicate that the stool antigen test has an acceptable level of accuracy.

Objectives: Our objective was to investigate the prevalence of $H$. pylori infection in Khuzestan province, south-west of Iran by stool antigen test and to evaluate possible risk factors for the H. pylori infection.

Patients and Methods: In this study, from September to October 2009, 861 healthy individuals aged 0-80 years were sampled by cluster sampling from 4.5 million inhabitants of the province. Infection with $H$. pylori was evaluated by detection of $H$. pylori antigens in stool (HpSA). Epidemiologic data of each subject were determined by filling up a questionnaire.

Results: The overall HpSA positivity was $(53.5 \%, \mathrm{CI} 95 \%=50.2-56.84 \%)$ and the mean age of infected cases was greater than that of non-infected ones (29.2 yrs vs. $24.5 \mathrm{yrs})(\mathrm{P}<0.001)$. HpSA positivity increased with age. The peak prevalence was reached in the $41-50$ years age group (66\%). No association was detected between $H$. pylori positivity and gender. Additionally, there was no significant relationship between $H$. pylori infection and previous hospital admission, gastrointestinal symptoms, and living area $(P>0.05)$.

Conclusions: H. pylori infection is highly prevalent (57\%) in Khuzestan province, south-west of Iran. Low educational levels, low socioeconomic jobs, and increasing age were related to high prevalence of $H$. pylori infection in this area.

Keywords: Helicobacter pylori; Stool antigen test; Iran

Copyright (c) 2013, Kowsar Corp.; Published by Kowsar Corp.

Article type: Research Article; Received: 21 Feb 2012, Revised: 11 Apr 2012, Accepted: 20 Jun 2012; DOI: 10.5812/jjm.4545

-Implication for health policy/practice/research/medical education:

We described the study and after they agreed, a day was fixed as enrollment day and all the family members present on that day were enrolled subject to the inclusion and exclusion criteria. Each family provided with a consent form to be signed by parents. The study was approved by our Ethical Committee.

PPlease cite this paper as:

Talaaizadeh AH, Borhani M, Moosavian M, Rafiei A, Neisi AK, et al. Prevalence of Helicobacter pylori Infection Detected by Stool Antigen Test in Khuzestan Province, South-West of Iran from September to October 2009,: A Population-Based Study. Jundishapur J Microbiol. 2013;6(2):100-104. DOI: 10.5812/jjm.4545

Copyright (C) 2013, Kowsar Corp.; Published by Kowsar Corp.

This is an Open Access article distributed under the terms of the Creative Commons Attribution License (http://creativecommons.org/licenses/by/3.0), which permits unrestricted use, distribution, and reproduction in any medium, provided the original work is properly cited. 


\section{Background}

Helicobacter pylori has been associated with gastritis, peptic ulcers, and gastric carcinoma $(1,2)$. Although infection with $H$. pylori is a global health problem, its prevalence is different among countries (3). This difference reflects socioeconomic factors including large families, crowded living conditions, and poor sanitation (4), but ethnicity may contribute independently (5). It is now generally agreed that $H$. pylori infections are acquired during childhood or adolescence in developing as well as developed countries (6).

Despite its great prevalence in our country, epidemiologic studies of $H$. pylori infection is limited. A recent study performed by histopathology in Ardabil, northwest of Iran, revealed about $90 \%$ of $H$. pylori infection in the normal population, older than 40 years old (7). There are several techniques available for detection of $H$. pylori. There is evidence that infected individuals excrete $H$. pylori in feces, since the pathogen could be detected in stool specimens by an antigen enzyme immunoassay (EIA).

Many studies support the diagnostic value of $H$. pylori antigens in stool samples by enzyme immunoassay (EIA) (8).This test was approved in 1998 for both diagnosis and monitoring the response to treatment of $H$. pylori infection in adult patients (9). Recently, a study performed by Falsafi $\mathrm{T}$ et al. using stool test for detection of $H$. pylori antigen in children and adolescents from Tehran demonstrated a high prevalence of infection (70\%) in cases with a family history of $H$. pylori infection or peptic ulcer disease (10).

\section{Objectives}

The availability of non-invasive antigen enzyme immunoassay (EIA) made it possible to carry out the present study to determine the prevalence rates of $H$. pylori infection in general population in Khuzestan province, southwest of Iran.

\section{Patients and Methods}

Population of Khuzestan province in south-west of Iran is around 4.5 million with various socioeconomic statuses. The area was visited and homes were chosen by cluster sampling according to study design and research methodology. We described the study to the habitants and after their agreement to cooperation, an enrollment date was fixed and all the family members present in that date were enrolled as subjects to the inclusion and exclusion criteria. Each family was provided with a consent form to be signed by parents. The study was approved by our Ethical Committee.

\subsection{Inclusion Criteria}

The studied individuals were healthy, aged 0-80 years, washed out for 30 days of any medication such as H2-receptor antagonists, acid pump inhibitors, non-steroidal anti-inflammatory drugs, or bismuth compounds that influenced $H$. pylori detection.

\subsection{Data Collection}

On the enrollment date, questionnaire forms were collected back and dates of birth and other data of the family members were noted. A unique identification (ID) number was assigned for each family member. All subjects were interviewed and personal, socioeconomic status, parents' educational level, environmental, and geographical data were obtained. From September to October 2009, 861 persons were sampled in the province. Subjects were asked to collect a specimen from their first stool.

Patients with recent history of treatment for $H$. pylori infection or antibiotic use for other purposes were excluded. Stool samples were stored at $-70{ }^{\circ} \mathrm{C}$ until performing the test that was independently performed by the Tropical Disease Research Center laboratory. The stool specimens were analyzed for $H$. pylori antigen using HpSA immunoassay as described by its manufacturer. A commercial kit, STRA (Italy) was used. The fecal sample was mixed with $200 \mu \mathrm{L}$ of the sample diluents. One drop of enzyme conjugates was added to the micro wells, which were incubated for 1 hour at room temperature and washed. The reaction was terminated with one drop of stop solution and the results were read by ELISA system. A particular cut-off value was considered positive as recommended by the manufacturer; the absorbance was read at both single (450-nm) and dual (450/630-nm) wavelengths. Positive and negative controls were run with each batch of samples. A positive test was indicated by a yellow color and a negative test was either colorless or faint yellow.

We analyzed the interview data and stool antigen tests by statistical package of WIN SPSS 15 and Stata 10; linear and logistic regression analyses were used as appropriate. Data were presented as proportions, mean \pm 2 SE; the Student's t-test was used for comparison of two means, and the chi-square test for multiple proportions.

\section{Results}

The overall HpSA positivity was $(53.5 \%, C I 95 \%=50.2$ $56.84 \%$ ).the mean age of infected cases was greater than that of non-infected ones $(29.2 \pm 1.54$ years vs. $24.5 \pm 1.8$ years $)(P>0.001)$. HpSA positivity increased with age. The peak prevalence was reached in the 41-50 years age group (66\%), with a relatively stable prevalence, thereafter. The specific prevalence of $H$. pylori positivity for each age group in the total sample is shown in Table 1. 
Table 1. Prevalence of H. pylori Stool Antigen (HpSA) Among 861 People in Khuzestan Province, South-West of Iran by Age Groups

\begin{tabular}{lll}
\hline Age Group, $\mathbf{y}$ & $\begin{array}{l}\text { HPSA Positive, No. } \\
(\%)\end{array}$ & $\begin{array}{l}\text { Total HPSA Positive } \\
\text { Cases, \% }\end{array}$ \\
\hline $\mathbf{0 - 1 0}$ & $53(33)$ & 11.5 \\
\hline $\mathbf{1 1 - 2 0}$ & $104(53.6)$ & 22.6 \\
\hline $\mathbf{2 1 - 3 0}$ & $119(60.7)$ & 25.8 \\
$\mathbf{3 1 - 4 0}$ & $78(59.1)$ & 17 \\
$\mathbf{4 1 - 5 0}$ & $58(66)$ & 12.6 \\
\hline $\mathbf{5 1 - 6 0}$ & $29(59.2)$ & 6.3 \\
\hline $\mathbf{6 0}<$ & $20(48.8)$ & 4.3 \\
\hline
\end{tabular}

Risk factors to $H$. pylori infection according to univariate analysis are shown in Table 2 .

Table 2. Risk Factors to H. pylori Infection According to Univariate Analysis

\begin{tabular}{lll}
\hline Risk Factor & Crude Odds Ratio & $P$ value \\
\hline Age group, & \multicolumn{2}{l}{} \\
\hline 0-10 & Reference group & $P<0.001$ \\
\hline $\mathbf{4 1 - 5 0}$ & 3.9 & $P<0.001$ \\
\hline Education & & \\
\hline Middle school & Reference group & $P<0.001$ \\
\hline Illiterate & 1.6 & \\
\hline Job & & \\
\hline Student & Reference group & $P<0.001$ \\
\hline Farmer & 3.03 & \\
\hline
\end{tabular}

The infection was significantly associated with age, job, and lower educational level (lower high school level) at univariate analysis $(P<0.001)$ (Figures 1 and 2$)$.

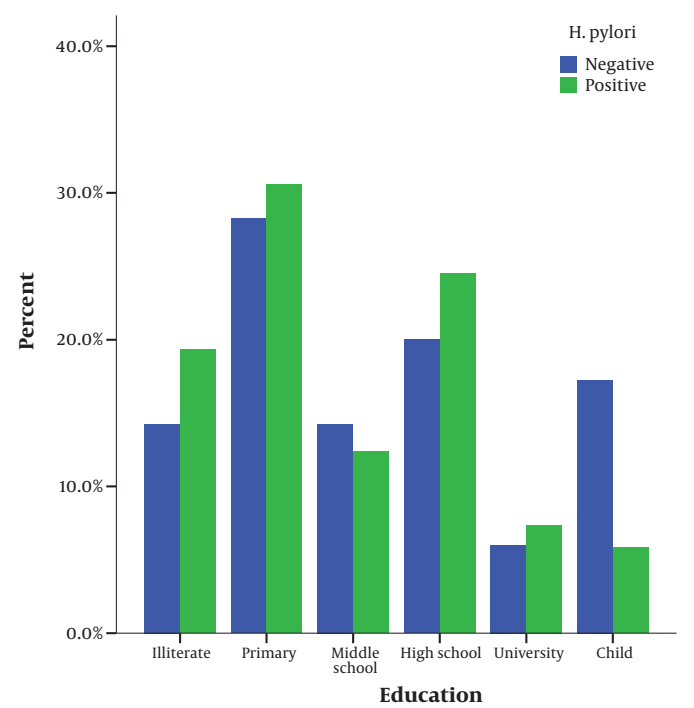

Figure 1. Prevalence of H. pylori Stool Antigen (HpSA) in Different Educational Groups

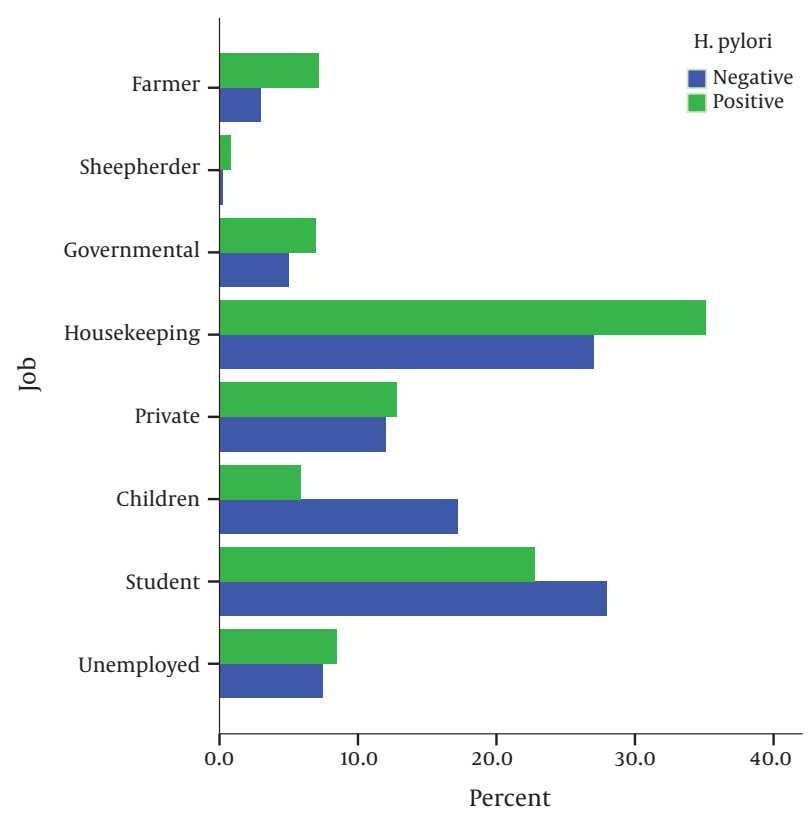

Figure 2. Prevalence of H. pylori Stool Antigen (HpSA) in Different Job Groups

In relation to access to facilities like personal computer, electrical washing machine, or internet, there were no significant differences by $H$. pylori stool antigen status $(P>$ 0.07). Additionally, there was no significant relationship between $H$. pylori infection and sex (male \& female), previous hospital admission, gastrointestinal symptoms, and living area. $(P>0.05)$.

\section{Discussion}

H. pylori infection is thought to play an etiologic role in several gastro-duodenal diseases. In epidemiological studies, H. pylori antigens (HpSA) in stool could offer high sensitivity and specificity (9). HpSA is a noninvasive method for determining the presence of $H$. pylori organisms. This study showed high infection rates of $H$. pylori among adults, children, and teenagers living in our community. Overall, 50-57\% of the study population was infected with H. pylori. HpSA positivity increased with age. The peak prevalence was reached in the $41-50$ years age group (66\%) with a relatively stable prevalence, thereafter. A similar trend has been observed in other countries, since the acquisition of $H$. pylori is known to occur mostly during the childhood.

This corresponds very closely to figures from other developing countries, e.g. $63 \%$ in Turkey and Tehran $(10,11)$, but lower than India (80\%) (12), and Pakistan (79\%) (13). The lower rate of infection among Iranian adults might be the result of frequent antibiotic usage among Iranian society or gradual improvement of socioeconomic status during the last two decades.

Our result is lower than that shown in previous studies in our country, i.e. $69.0 \%$ in Tehran and 79.4\% in Kerman 
$(14,15)$. This may be due to the fact that those studies were not population-based; only volunteers or referrals to clinics had been examined. In addition, another reason for such differences is the method of $H$. pylori diagnosis in those populations that was H. pylori IgG antibodies. Among the noninvasive detection methods that are practical for population-based studies, the urea breath test (UBT) and stool antigen tests (HpSA) are considered as the most accurate, while serology is the least costly and most widely available. $H$. pylori seroprevalence studies most commonly used IgG which has the disadvantage of non-differentiation value between current and past infections; whereas H. pylori IgG antibodies often decline to negative levels once the infection has resolved, the frequency and timing of this occurrence differs substantially across populations (16).

Previous investigations have shown the importance of sex and age in the acquisition of $H$. pylori infection (17). Some studies have shown no sex difference in the prevalence of $H$. pylori $(18,19)$ but in a study in Iran, $H$. pylori prevalence was higher in males than in females (20).In our study there was no significant relationship between $H$. pylori infection and sex. We found an inverse relationship between $H$. pylori prevalence and educational level. $H$. pylori infection was higher in subjects of lower compared to those with higher educational levels. This difference was statistically significant $(P<0.001)$. In this study, high- educated participants had a lower frequency of $H$. pylori infection compared to those who were low-educated ( $7.4 \%$ vs $30.6 \%$, respectively).

Low socioeconomic jobs were associated with a higher prevalence of $H$. pylori colonization in our studied population. This result could reflect the difference in the standards of living conditions between the two groups of studied population. It further supports the consensus that low socioeconomic status is associated with increase in prevalence of H. pylori infection (21). Regarding the job groups, our investigation found that jobs with poor hygiene were associated with a higher risk of acquiring $H$. pylori infection. For example, the study showed a higher prevalence of $H$. pylori infection among illiterate farmers than in educated professionals with odds ratio of 3.03 ( $P$ $<0.001)$. Consistent with other studies, we could not find any significant relationship between access to facilities of adulthood like personal computer, electrical washing machine, or internet and $H$. pylori infection rate (22).

The present study had limitations. Although the detection of $H$. pylori antigen in stool has a sensitivity and specificity of 90-95\%, other tests (such as urease test and culture of the organism from gastric biopsies) or combination tests may have improved our detection rate $(6,9)$. Nevertheless, this study is the first in Khuzestan province, south-west of Iran and provide insights into the epidemiology of $H$. pylori in this area. In addition, longitudinal data on $H$. pylori-related clinical events such as peptic ulcer disease and gastric cancer would allow the assess- ment of the impact of $H$. pylori in our community.

To evaluate the accuracy of stool antigen test, an endoscopic evaluation and biopsy or a recently developed monoclonal antibody is useful. In this study, we did not have such control groups; this is a limitation in our study. The aim of this study was to estimate the prevalence of H. pylori infection in our area; therefore other studies are needed to reach to this goal. Other prospective cohort studies are required to clearly and define the aspects of H. pylori infection epidemiology in this area.

In conclusion, the study shows $H$. pylori infection is highly prevalent (57\%) in Khuzestan province, south-west of Iran. Based on our findings, H. pylori infection rate obtained from this study is lower than those previously described, and correlates with increasing age, but not gender. Low educational level and the job group of the study subjects were found as the possible risk factors related to considerable rate of $H$. pylori infection among our community.

\section{Acknowledgements}

This study was funded by Tropical and Infection Research Center and Research Institute for Infectious Diseases of Digestive system, Ahvaz Jundishapur University of Medical Sciences, Ahvaz, Iran.

\section{Financial Disclosure}

Financial support for this study was provided by Research Deputy of Ahwaz Jundishapur University of Medical Sciences.

\section{Funding/Support}

None declared.

\section{Authors' Contribution}

None declared.

\section{References}

1. Cover TL, Blaser MJ. Helicobacter pylori factors associated with disease. Gastroenterology. 1999;117(1):257-61.

2. Parsonnet J, Friedman GD, Vandersteen DP, Chang Y, Vogelman $\mathrm{JH}$, Orentreich $\mathrm{N}$, et al. Helicobacter pylori infection and the risk of gastric carcinoma. N Engl J Med.1991;325(16):1127-31.

3. Suerbaum S, Michetti P. Helicobacter pylori infection. $N$ Engl J Med. 2002;347(15):1175-86.

4. Frenck RW, Jr., Clemens J. Helicobacter in the developing world. Microbes Infect. 2003;5(8):705-13.

5. Fraser AG, Scragg R, Metcalf P, McCullough S, Yeates NJ. Prevalence of Helicobacter pylori infection in different ethnic groups in New Zealand children and adults. Aust $N$ Z J Med. 1996;26(5):646-51.

6. Ni YH, Lin JT, Huang SF, Yang JC, Chang MH. Accurate diagnosis of Helicobacter pylori infection by stool antigen test and 6 other currently available tests in children. J Pediatr. 2000;136(6):823-7.

7. Malekzadeh R, Sotoudeh M, Derakhshan MH, Mikaeli J, Yazdanbod A, Merat S, et al. Prevalence of gastric precancerous lesions in Ardabil, a high incidence province for gastric adenocarcinoma in the northwest of Iran. J Clin Pathol. 2004;57(1):37-42. 
8. Braden B, Posselt HG, Ahrens P, Kitz R, Dietrich CF, Caspary WF. New immunoassay in stool provides an accurate noninvasive diagnostic method for Helicobacter pylori screening in children. Pediatrics. 2000;106(1 Pt 1):115-7.

9. Oderda G, Rapa A, Ronchi B, Lerro P, Pastore M, Staiano A, et al. Detection of Helicobacter pylori in stool specimens by non-invasive antigen enzyme immunoassay in children: multicentre Italian study. BMJ. 2000;320(7231):347-8.

10. Falsafi T, Valizadeh N, Sepehr S, Najafi M. Application of a stool antigen test to evaluate the incidence of Helicobacter pylori infection in children and adolescents from Tehran, Iran. Clin Diagn Lab Immunol. 2005;12(9):1094-7.

11. Ertem D, Harmanci H, Pehlivanoglu E. Helicobacter pylori infection in Turkish preschool and school children: role of socioeconomic factors and breast feeding. Turk J Pediatr. 2003;45(2):114-22

12. Graham DY, Adam E, Reddy GT, Agarwal JP, Agarwal R, Evans DJ Jr., et al. Seroepidemiology of Helicobacter pylori infection in India. Comparison of developing and developed countries. Dig Dis Sci.1991;36(8):1084-8.

13. Abbas Z, Jafri W, Khan AH, Shah MA. Prevalence of Helicobacter pylori antibodies in endoscopy personnel and non-medical volunteers of Karachi.J Pak Med Assoc. 1998;48(7):201-3.

14. Nouraie M, Latifi-Navid S, Rezvan H, Radmard AR, Maghsudlu M, Zaer-Rezaii H, et al. Childhood hygienic practice and family education status determine the prevalence of Helicobacter pylori infection in Iran. Helicobacter. 2009;14(1):40-6.
15. Zahedi MJ, Darvish S, Hayatbakhsh M, Atapour M. Relative frequency of Helicobacter pylori infection in the city of Kerman in 2000. J Kerman Univ Med Sci. 2002;9(3):140-5.

16. Goodman KJ, Cockburn M. The role of epidemiology in understanding the health effects of Helicobacter pylori. Epidemiology. 2001;12(2):266-71.

17. Goodman KJ, Correa P. The transmission of Helicobacter pylori A critical review of the evidence. Int JEpidemiol.1995;24(5):875-87.

18. Altuglu I, Sayiner AA, Ozacar T, Egemen A, Bilgic A. Seroprevalence of Helicobacter pylori in a pediatric population. Turk J Pediatr. 2001;43(2):125-7.

19. Graham DY, Malaty HM, Evans DG, Evans DJ, Jr., Klein PD, Adam E Epidemiology of Helicobacter pylori in an asymptomatic population in the United States. Effect of age, race, and socioeconomic status. Gastroenterology. 1991;100(6):1495-501.

20. Jafarzadeh A, Ahmedi-Kahanali J, Bahrami M, Taghipour Z. Seroprevalence of anti-Helicobacter pylori and anti-CagA antibodies among healthy children according to age, sex, $\mathrm{ABO}$ blood groups and Rh status in south-east of Iran. Turk J Gastroenterol. 2007;18(3):165-71.

21. Banatvala N, Mayo K, Megraud F, Jennings R, Deeks JJ, Feldman RA. The cohort effect and Helicobacter pylori. J Infect Dis. 1993;168(1):219-21.

22. Zaterka S, Eisig JN, Chinzon D, Rothstein W. Factors related to Helicobacter pylori prevalence in an adult population in Brazil. Helicobacter. 2007;12(1):82-8. 